I. Vroh Bi • A. Maquet · J.-P. Baudoin · P. du Jardin J.M. Jacquemin · G. Mergeai

\title{
Breeding for "low-gossypol seed and high-gossypol plants" in upland cotton. Analysis of tri-species hybrids and backcross progenies using AFLPs and mapped RFLPs
}

Received: 5 January 1999 / Accepted: 17 June 1999

\begin{abstract}
This work aims at breeding upland cotton [Gossypium hirsutum L., 2(AD) $)_{1}$ genome] with a reduced level of gossypol in the seeds for optimal food and feed uses, and a high gossypol level in the remaining organs for resistance to pests. Two tri-species Gossypium hybrids, (G. thurberi-G. sturtianum-G. hirsutum and $G$. hirsutum-G. raimondii-G. sturtianum) including $G$. sturtianum $\left(2 \mathrm{C}_{1}\right)$ as a donor, $G$. thurberi $\left(2 \mathrm{D}_{1}\right)$ and $G$. raimondii $\left(2 \mathrm{D}_{5}\right)$ as a bridge species, were created. Recurrent selection initiated with these tri-species hybrids produced backcross (BC) progenies expressing the "lowgossypol seed and high-gossypol plant" trait at different levels. We used AFLP markers to assess the genetic similarity among the germplasm and RFLP probes to tag the introgression of specific chomosome segments from the parental species. Five pairs of AFLP primers generated 477 fragments, among which 417 (87.4\%) were polymorphic. The genetic similarity between the upland cotton and the wild species ranged from 29.5 to $43.2 \%$, while similarity reached $80 \%$ between upland cotton and $\mathrm{BC} 3$ plants. Introgression of species-specific AFLPs was evident from all the parental species and confirmed the hybrid origin of the analyzed progenies. Southern-blot analysis based on 49 RFLP probes allowed us to trace the introgression of parental DNA segments in the trispecies hybrids and in three generations of backcross. In-
\end{abstract}

Communicated by G. Wenzel

I. Vroh Bi ( $)$ - A. Maquet · J.-P. Baudoin · G. Mergeai

Unité de Phytotechnie des Régions Intertropicales,

Faculté Universitaire des Sciences Agronomiques,

2 Passage des déportés, B-5030 Gembloux, Belgium

e-mail: vroh10@hot.mail.com

Fax: 32-81-61-45-44

P. du Jardin

Unité de Biologie Végétale,

Faculté Universitaire des Sciences Agronomiques,

2 Passage des déportés B-5030 Gembloux, Belgium

J.M. Jacquemin

Département de Biotechnologie,

Centre de Recherche Agronomique 234,

chée de charferoi 5030 Gembloux, Belgium trogression was evident from 11, 8 and 7 linkage groups of G. sturtianum, G. raimondii and G. thurberi respectively. The types of introgression revealed by RFLP probes are discussed, and breeding schemes to enhance recombination are proposed. The ability to trace DNA segments of known chromosomal locations from the donor $G$. sturtianum through segregating generations is a starting point to map the "low-gossypol seed and highgossypol plant" traits.

Key words Cotton - Gossypol - Wide hybridization . Backcrossing · DNA markers - AFLP · RFLP . Introgression

\section{Introduction}

Gossypium contains about 50 diploid and tetraploid species distributed worldwide in both tropical and subtropical areas. The diploid species $(2 n=2 x=26)$ fall into eight different cytotypes designated A, B, C, D, E, F, G and K (Endrizzi et al. 1985; Stewart 1994). The tetraploid species $(2 \mathrm{n}=4 x=52$, AADD) contain two distinct subgenomes which are related to the A genome of the Asiatic cultivated diploid species and the D genome of the American wild diploid species (Endrizzi et al. 1985). Four Gossypium species namely G. arboreum, G. barbadense, G. herbaceum and G. hirsutum are cultivated, the upland cotton (G. hirsutum L.) being the most important.

Cotton is the leading fiber crop, but it also ranks high among food crops (Lusas and Jividen 1987; Alford et al. 1996). In fact, cotton is the second best potential source of plant proteins and the fifth best oil-producing plant (Texier 1993). One of the main traits characterizing the Gossypium genus is the presence of pigment glands containing terpenoid aldehydes, namely gossypol, throughout the plant. The presence of glands in cultivated cottonseed has economic disavantages to the seed- and oilprocessing industry because gossypol is toxic to non-ruminant animals, including humans. During the 1960s and 1970 s, there was great interest in the genetics of gossy- 
pol-content in cotton. The alleles $g l_{2}$ and $g l_{3}$ identified by McMichael (1960) effectively removed gossypol from seed and foliage, enabling the use of cottonseed in food and feed without the deleterious effect of gossypol. These glandless phenotypes were considered agronomically important because gossypol was not stored in the embryo. It has been shown that terpenoid aldehydes present in the cotton plant confer natural resistance to various insect, fungal, and bacterial diseases (Stipanovic et al. 1975; Altman et al. 1990; Calhoun 1997). However, glandless plants are completely devoid of these compounds. The ideal phenotype appears to be a combination of "low-gossypol seed and high-gossypol plant" traits in the same variety. In Gossypium, the "glandlessseed and glanded-plant" trait exists only in some Australian wild diploid species belonging to the Sturtia and Hibiscoidea sections (Brubaker et al. 1996). Although these Australian cottons of $\mathrm{C}$ and $\mathrm{G}$ genomes are phylogenetically remote from the upland cotton, they offer very interesting possibilities to breeders (Stewart 1994; Brubaker et al. 1996). In these plants, the genes involved in gland morphogenesis seem to be controlled by a repressive mechanism which acts until the cotyledons open and the young plantlets begin to form chlorophyll (Mergeai 1992). The objective of our research is to introgress this repressive mechanism from $G$. sturtianum $\left(2 \mathrm{n}=2 x=26,2 \mathrm{C}_{1}\right.$ genome $)$ into the tetraploid upland cotton G. hirsutum.

During the past few years, new strategies based on marker-assisted selection have been proposed to reduce time and effort in developing new varieties. The use of DNA markers to enhance plant breeding efforts has been described in detail by numerous investigators (Tanskley et al. 1989; Paterson et al. 1991; Dudley 1993; Lee 1998). However, reports on the application of DNA markers to cotton improvement remain scarce compared to the importance of this crop. Random amplified polymorphic DNA was used to fingerprint cotton cultivars (Multani and Lyon 1995), to evaluate diversity in elite cotton germplasm (Tatineni et al. 1996; Iqbal et al. 1997) and to assist wide hybridization and recurrent crosses in cotton (Vroh Bi et al. 1997; Mergeai et al. 1998). Few applications of restriction fragment length polymorphism to cotton have been reported (Wang et al. 1995; Shappley et al. 1996; Meredith and Brown 1998). To-date, an RFLP map of cotton is in construction (Reinisch et al. 1994) and offers a valuable new tool to analyze introgression in breeding programs.

Amplified fragment length polymorphism is a DNA fingerprinting technique capable of detecting several loci in a single PCR reaction (Zabeau 1993; Vos et al. 1995). This technique has been successfully applied in tomato (Thomas et al. 1995), rice (Zhu et al. 1998), barley (Becker et al. 1995), potato (Meksem et al. 1995), as well as in other crops (Hansen et al. 1999; Shan et al. 1999).

We carried out wide hybridization, backcrossing and selfing to produce seeds, and in vitro culture of seed embryos to obtain mature plants (Vroh Bi et al. 1999). The

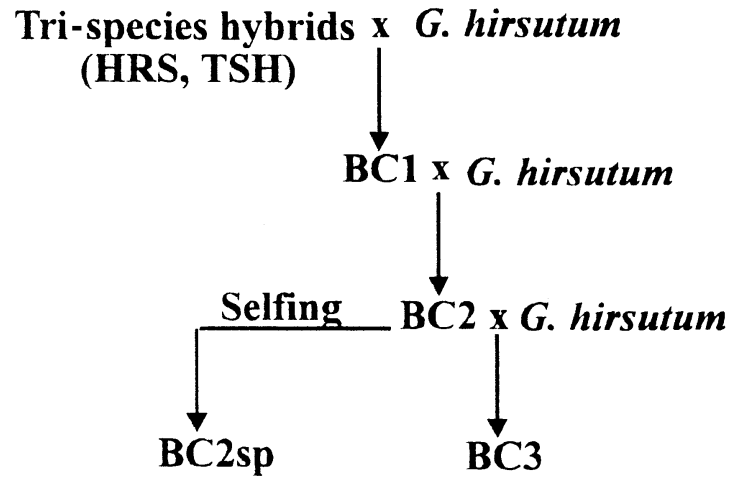

Fig. 1 Pedigree of backcross progenies obtained from the tri-species hybrids $G$. hirsutum-G. raimondii-G. sturtianum (HRS) and G. thurberi-G. sturtianum-G. hirsutum (TSH)

objectives of the present study were to: (1) report the gossypol gland behaviour in backcross seedlings after germination, as well as gland distribution on the flower buds which are very sensitive organs to insects, (2) test the ability of AFLP to establish genetic relatedness between parents and progenies of cotton under recurrent selection, and (3) determine the chromosomal composition of hybrids and backcross progenies using a set of available RFLP markers with known map locations.

\section{Materials and methods}

\section{Plant materials}

Plant materials include two tri-species hybrids containing G. hirsutum $2(\mathrm{AD})_{1}$ as the recipient species, $G$. sturtianum $\left(2 \mathrm{C}_{1}\right)$ as the donor parent, and two American wild diploids G. thurberi $\left(2 \mathrm{D}_{1}\right)$ and $G$. raimondii $\left(2 \mathrm{D}_{5}\right)$ as bridge species. These hybrids are respectively designated by the initials TSH for [ $G$. thurberi $\times G$. sturtianum $)$ doubled $\times G$. hirsutum $]$ and HRS for $[(G$. hirsutum $\times G$. raimondii) doubled $\times G$. sturtianum]. The chromosome numbers of the intermediate bispecific hybrids were doubled with colchicine. Pedigrees of the two tri-species hybrids are detailed in Vroh Bi et al. (1998). Both hybrids were involved in backcrosses to produce backcross $(\mathrm{BC})$ or backcross-selfed (BCsp) progenies as described in Fig. 1. In total, the two tri-species hybrids and $38 \mathrm{BC}$ progenies including $12 \mathrm{BC} 1,4 \mathrm{BC} 2,10 \mathrm{BC} 2 \mathrm{sp}$ and $12 \mathrm{BC} 3$ were analyzed. Total genomic DNA was extracted from the studied plants as described by Vroh Bi et al. (1996).

\section{Gossypol gland evaluation}

The gossypol gland density of naked embryos was assessed under a binocular microscope according to a visual scale ranging from 0 , for totally glandless embryos to 10 , which is the gland level in normally glanded cultivated cottonseed. The in vitro culture of seed embryos was performed as described by Vroh Bi et al. (1999). After germination, the evolution of the gland level of in vitro seedlings was observed daily, considering the gland level in seedlings of $G$. hirsutum and $G$. sturtianum as controls. Leaves and stems of the backcross progenies were evaluated to assess the recovery of the highest level of gossypol glands during the growth of seedlings derived from low-gossypol seeds. The presence of glands on the calyx crown, a characteristic termed high glanding, was also scored among the mature plants. This trait is reported to be highly correlated with resistance to the main insect pests in cotton (Calhoun 1997). 
AFLP analysis

The AFLP reactions were performed with the AFLP Analysis System I kit (Life Technologies, Merelbeke, Belgium). Restriction endonuclease-digestion of total genomic DNA, ligation of adapters, PCR reactions, primer labelling and electrophoresis of amplified fragments were all performed following the manufacturer's protocol. In short, $250 \mathrm{ng}$ of genomic DNA were digested with $E c o$ RI and MseI, ligated to adapters and amplified in two successive steps. In the first reaction, called pre-amplification, genomic DNA is amplified with AFLP primers having one selective nucleotide each. The PCR products of the pre-amplification reaction were diluted 50-fold and used as templates for selective amplification using two AFLP primers containing three selective nucleotides each. Before amplification, the EcoRI selective primer is labelled by phosphorylating its $5^{\prime}$ end with alpha-[ $\left.{ }^{32} \mathrm{P}\right]$ ATP using T4 polynucleotide kinase. The following five primer combinations were employed in this study: $\mathrm{C} 1=E c o R \mathrm{I}+\mathrm{AAC} / M s e \mathrm{I}+\mathrm{CAA}$, $\mathrm{C} 2=E c o \mathrm{RI}+\mathrm{AAC} / M s e \mathrm{I}+\mathrm{CTT}, \mathrm{C} 3=E c o \mathrm{RI}+\mathrm{AGG} / M s e \mathrm{I}+\mathrm{CTT}), \mathrm{C} 6=$ $E c o \mathrm{RI}+\mathrm{ACT} / M s e \mathrm{I}+\mathrm{CAG}, \mathrm{C} 9=E c o \mathrm{RI}+\mathrm{ACG} / M s e \mathrm{I}+\mathrm{CTA}$. The $\mathrm{PCR}$ reactions were performed in a Perkin-Elmer 2400. Amplification products were resolved in $6 \%$ denaturing polyacrylamide gels by loading $3 \mu \mathrm{l}$ of each sample. Gels were exposed at $-80^{\circ} \mathrm{C}$ overnight to Biomax MR X-ray film (Kodak).

\section{Data analysis}

AFLP bands were scored as present (1) or absent (0). The genetic similarity (GS) based on pairwise comparisons was calculated according to Jaccard's coefficient (Jaccard 1908). GS(ij)= $1-\mathrm{M} / \mathrm{Ti}-\mathrm{Tj}-\mathrm{M}$ where GS is the measure of genetic similarity between individuals $\mathrm{i}$ and $\mathrm{j}, \mathrm{M}$ is the number of band matches between $\mathrm{i}$ and $\mathrm{j}$, Ti and $\mathrm{Tj}$ the total number of bands in $\mathrm{i}$ and $\mathrm{j}$ respectively. A dendrogram based on these coefficients was constructed using the unweighted pair group method average (UPGMA) on the SYSTAT software package, version 8.0 (SPSS Inc., Chicago, Ill.).

\section{RFLP analysis}

Forty nine available inserts were used for analysis. These clones, originally selected from the RFLP map of cotton (Reinisch et al. 1994), were kindly provided by Dr. A.H. Paterson (Texas A\&M University). Inserts were amplified by PCR using M13 forward and reverse primers (SP010 and SP030, Operon, Alameda, Calif.). PCR reactions were carried out in a 100- $\mu \mathrm{l} \mathrm{vol} \mathrm{containing} 10 \mu \mathrm{l}$ of reaction buffer (500 mM Tris-HCl, pH 8.5; $15 \mathrm{mM} \mathrm{MgCl}_{2}$ ), $2.5 \mathrm{mM} \mathrm{MgCl}$, $200 \mu \mathrm{M}$ of dNTPs, $0.25 \mu \mathrm{g}$ of each forward and reverse primer and $2.5 \mathrm{U}$ of Taq DNA polymerase (Amersham Pharmacia Biotech, Roosendaal, The Netherlands). The PCR conditions were as follows: $94^{\circ} \mathrm{C}$ for $5 \mathrm{~min} ; 25$ cycles of $94^{\circ} \mathrm{C}$ for $1 \mathrm{~min} 30 \mathrm{~s}, 45$ to $48^{\circ} \mathrm{C}$ (according to the clones) for $1 \mathrm{~min} 10 \mathrm{~s}$, and $72^{\circ} \mathrm{C}$ for $3 \mathrm{~min} 15 \mathrm{~s}$, followed by a final extension of $72^{\circ} \mathrm{C}$ for $7 \mathrm{~min}$. The amplifications were performed in a Techne PHC-3 thermal cycler. An aliquot of the PCR products was electrophoresed in $0.8 \%$ agarose to verify amplification of a single product. PCR products were separated from excess reaction components using microspin columns S-300 HR (Amersham Pharmacia Biotech, Roosendaal, The Netherlands). Restriction endonuclease digestion, Southern blotting, labelling and hybridization of RFLP probes were all performed as described by Reinisch et al. (1994) with the following modifications: $7 \mu \mathrm{g}$ of genomic DNA were digested with six restriction enzymes (BamHI, CfoI, EcoRI, EcoRV, HindIII and $X b a \mathrm{I}), 50 \mathrm{ng}$ of PCR-amplified fragment were labelled, $10 \mathrm{ml}$ of hybridization buffer were incubated at $65^{\circ} \mathrm{C}$ overnight in a Techne HB-1D hybridization oven, and filters were exposed to Kodak $\mathrm{X}$-OMAT-AR film with an intensifying screen for 1 week.

\section{Scoring for introgression}

Introgression from the wild species was assessed by analyzing profiles showing polymorphism between parental species for the tested probe/enzyme combinations. When the banding pattern of hybrids and $\mathrm{BC}$ progenies was similar to that of the wild parent for the RFLP markers, the result was considered "positive" and indicated introgression of the wild parent chromosome segment at the concerned RFLP locus. Flanking RFLP markers of the putative positive marker were then checked when available to determine the approximate size of the introgressed segments in centimorgans. When adjacent markers were "negative" for introgression, it was assumed that the recombination event occurred midway between the markers (Jena et al. 1992; Garcia et al. 1995).

\section{Results}

\section{Gossypol gland evaluation}

Backcrossing of the two tri-species hybrids and their progenies produced, in total, 192 seeds composed of 129 BC1, 23 BC2, 18 BC2sp and 22 BC3. Evaluation of seed gland level showed that nine seeds were glandless (level $0)$, eight seeds were completely glanded (10), 158 seeds had a gland level ranging from 1 to 9 , and the remaining 17 seeds were empty (devoid of embryos). Figure 2 shows an example of the gland level in seeds of parental species and backcross plants. The gland level in the cultivated species $G$. hirsutum is considered as the maximum in seeds and seedlings (level 10). After germination, the increase of gland level on organs of seedlings was observed simultaneously in the donor parent $(G$. sturtianum) and the $\mathrm{BC}$ progenies. When the radicule of the Australian species began to elongate 2 days after in vitro culture, glands appeared first on the higher part of the hypocotyl before the glandless cotyledons opened completely. The stem of the in vitro seedlings of $G$. sturtianum exhibited the highest level of glands 5 days after germination (data not shown). When the cotyledons turned to green, glands appeared on the margins of the cotyledonary leaves and increased in number with aging of the seedlings. The first true leaf emerging 1 week after germination was fully glanded and showed the gland pattern of a mature plant. In the $\mathrm{BC}$ progenies, recovery of the highest gland level in seedlings varied mainly between generations for a given seed gland level. In general, gland recovery in $\mathrm{BC} 1$ seedlings derived from lowgossypol seed was slower than that of the parents, most certainly due to their slow growth. The increase of gland level in BC2, BC2sp and BC3 progenies was intermediate between that of the cultivated parent $G$. hirsutum and the donor parent $G$. sturtianum. The tri-species hybrids and their progenies obtained by backcrossing to cultivated cotton contain the dominant alleles Gl2 and Gl3 of the two major genes conferring the totally glanded phenotype to cultivated cotton (given by the pollen). In these experiments the parental species used as controls and the BC progenies were obtained in the same conditions of in vitro culture of embryos, hardening and maintenance in the greenhouse (Vroh Bi et al. 1999). The low gland levels observed in seeds of BC progenies are thus due to a gene(s) introgressed from the Australian wild species G. sturtianum. The recovery of high gland levels in seedlings derived from low-gossypol seeds probably 

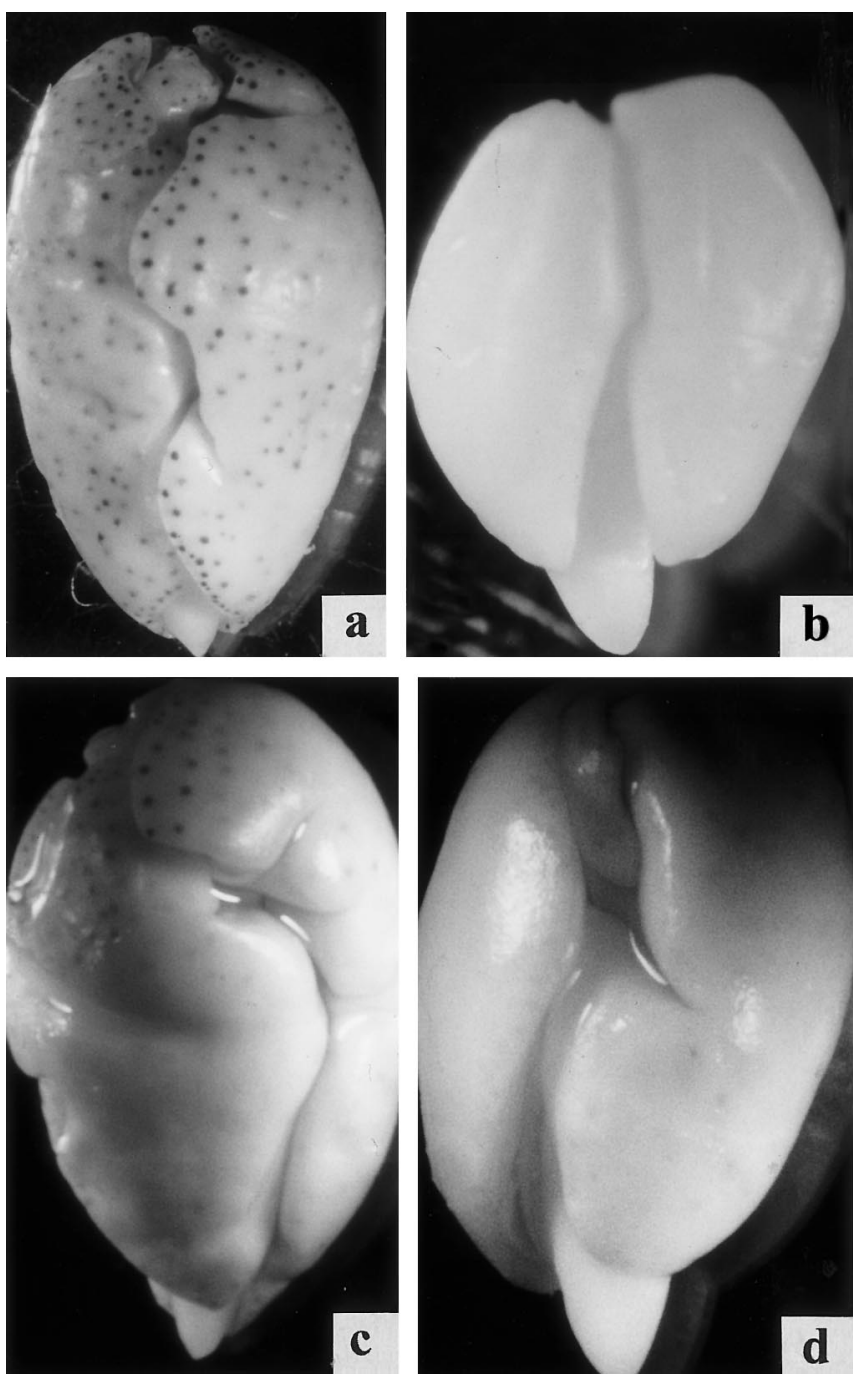

Fig. 2a-d Patterns of gossypol glands in seeds of parental species and backcross progenies. a Totally glanded seed of the cultivated upland cotton G. hirsutum (level 10). b Glandless seed of the donor G. sturtianum (level 0). c Low-gossypol BC3 seed (level 4). d Low-gossypol BC3 seed (level 1)

indicates that the repressive mechanism of G. sturtianum is acting in the analyzed plants. All the mature plants obtained in this study were glanded, but the shape and distribution of glands varied between plants and organs.

The studied plants were screened for the high-glanding phenotype (Fig. 3). The cultivated cotton variety $\mathrm{C} 2$ used in this study is normal glanding (absence of gossypol gland on the calyx crown). By contrast, the Australian species $G$. sturtianum has the high-glanding phenotype that can confer insect resistance to cotton plants. This character is inherited by the two tri-species hybrids (HRS, TSH), but the calyx crown of TSH was more glanded than that of HRS. Although the $\mathrm{BC}$ progenies were segregating for the high-glanding trait, calyx crowns of plants derived from TSH were more glanded than calyx crowns of progenies from HRS. Table 1 shows the distribution of the high-glanding trait in each
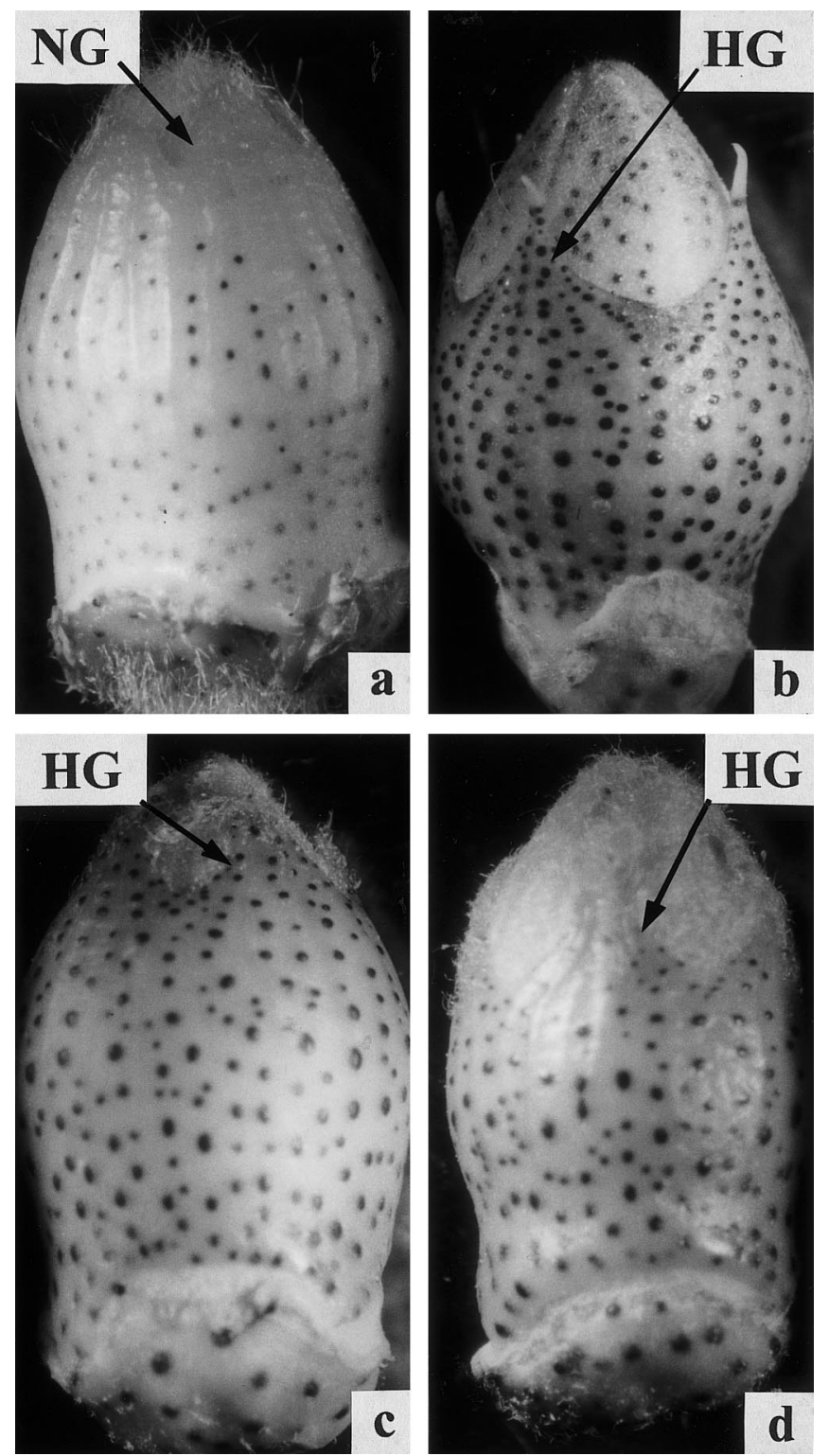

Fig. 3a-d Gossypol gland distribution on the calyx crown from parental species, tri-species hybrid and backcross progeny. a Normal glanding $(N G)$ in the cultivated upland cotton $G$. hirsutum. b High glanding $(H G)$ in the donor $G$. sturtianum. c High glanding in the tri-species hybrid TSH. d High glanding in a BC1 progeny derived from TSH and having glandless seed. Arrows indicate the calyx crown

Table 1 Segregation for the high-glanding trait in backcross generations

\begin{tabular}{llll}
\hline $\begin{array}{l}\text { Backcross } \\
\text { generations }\end{array}$ & $\begin{array}{l}\text { Number of } \\
\text { high glanding }\end{array}$ & $\begin{array}{l}\text { Number of } \\
\text { normal glanding }\end{array}$ & $\begin{array}{l}\text { Number of } \\
\text { plants observed }\end{array}$ \\
\hline BC1 & 11 & 1 & 12 \\
BC2 & 3 & 1 & 4 \\
BC2sp & 9 & 1 & 10 \\
BC3 & 5 & 7 & 12 \\
Total & 28 & 10 & 38 \\
\hline
\end{tabular}




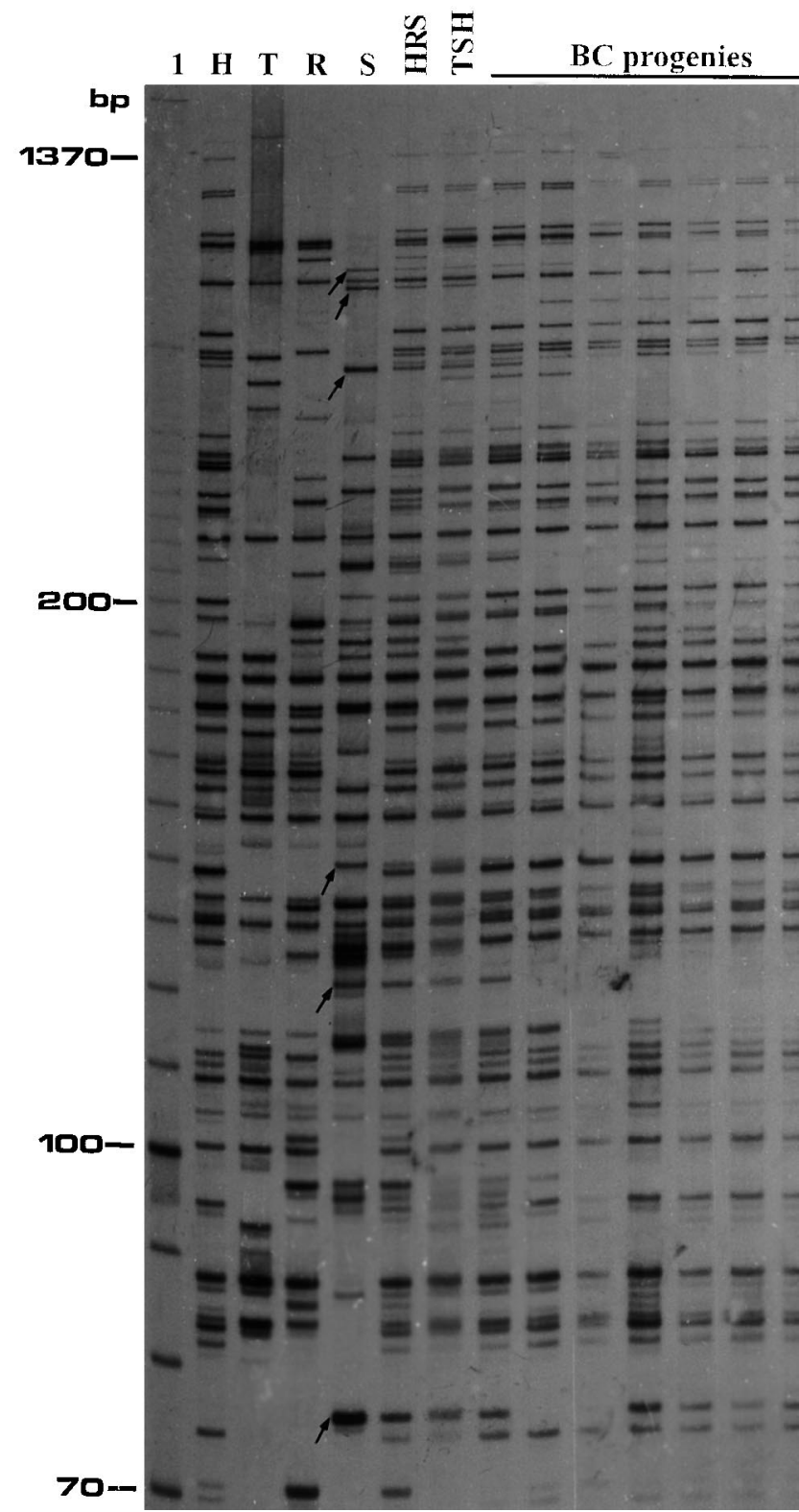

Fig. 4 AFLP patterns obtained from parental species and progenies using the primer pair $E c o \mathrm{RI}+\mathrm{AGG} / M s e \mathrm{I}+\mathrm{CTT}$. The first lane (1) is the AFLP DNA-ladder from Life Technologies Inc., $H=G$. hirsutum (C2), $T=G$. thurberi, $R=G$. raimondii, $S=G$. sturtianum, $H R S$ and TSH are the tri-species hybrids. AFLP markers specific to the donor $G$. sturtianum are indicated with arrows

backcross generation. The maintenance and segregation of this phenotype through backcrossing and selfing should allow the utilization of the present germplasm in breeding for cotton varieties resistant to insects.

\section{AFLP analysis}

The number of bands generated by each primer combination in the parental species ranged from 72 for C6 (EcoRI+ACT/MseI+CAG) to 132 for C2 (EcoRI+ $\mathrm{AAC} / \mathrm{Mse}+\mathrm{I}+\mathrm{CTT}$ ), with a mean of 96 bands. The five

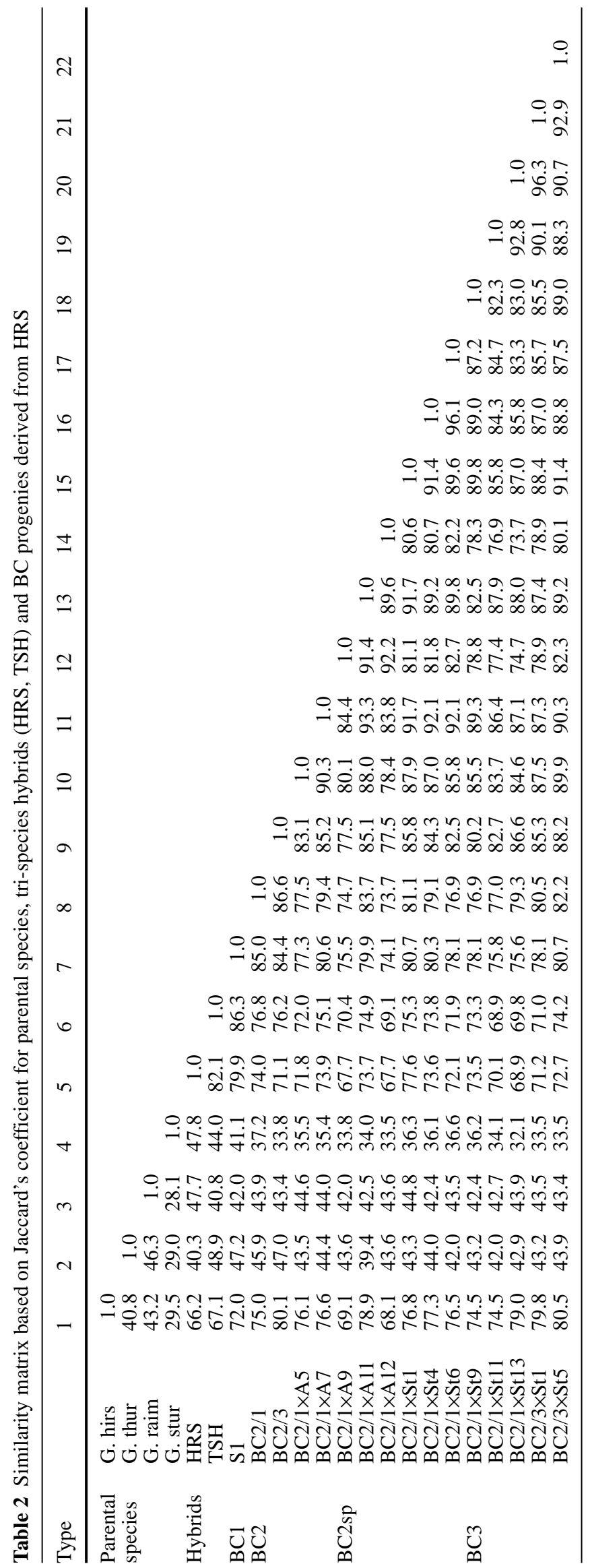


primer combinations amplified a total of 477 DNA fragments of which, 417 (87.4\%) were polymorphic. Figure 4 shows the AFLP pattern for the primer combination C3. The introgression of AFLP bands specific to each parent allowed the confirmation of the interspecific origin of the two hybrids TSH and HRS. Out of the 70 specific fragments of the donor parent G. sturtianum, 45 and 44 were present in the tri-species hybrids HRS and TSH respectively, and 43 were segregating in the $\mathrm{BC}$ progenies. Besides the polymorphic bands specific to each of the parental species (G. hirsutum, G. sturtianum, G. raimondii and $G$. thurberi), some polymorphic AFLPs were shared by two or three parents. Markers which are not transmitted to progenies at each generation are either located on chromosomes that are not transmitted during meiosis, or constitute markers undergoing recombinations that can modify the primer binding sites. Four specific markers of $G$. sturtianum (C genome) were systematically present in all the BC progenies. Such fragments should be located on the chromosomes that are preferentially transmitted to progenies, due to their higher pairing affinity with the chromosomes of the other parents, or else should correspond to repeated DNA dispersed throughout the donor genome of $G$. sturtianum $\left(2 \mathrm{C}_{1}\right)$.

The relatedness among the studied genotypes was assessed by similarity analysis using the coefficient of Jaccard (1908). Table 2 shows the similarity matrix obtained between parental species, tri-species hybrids and $\mathrm{BC}$ progenies. All the $\mathrm{BC} 2, \mathrm{BC} 2 \mathrm{sp}$ and $\mathrm{BC} 3$ shown in Table 2 were derived from a single $\mathrm{BC} 1$ plant (S1) obtained by pollinating HRS with $G$. hirsutum (C2 cultivar). The similarity between the cultivated species and the wild parents ranged from $29.5 \%$ to $43.2 \%$. Among the wild species, G. raimondii shared the highest similarity with G. hirsutum (43.2\%). This American wild diploid species was supposed to be the donor of the D subgenome in tetraploid upland cotton (Endrizzi et al. 1985). Both tri-species hybrids were closer to cultivated cotton than to the wild species used in the initial crosses, with $66.2 \%$ and $67.1 \%$ for HRS and TSH respectively. A dendrogram generated by UPGMA analysis allowed the grouping of the genotypes studied (Fig. 5). The positions of the parental species in the dendrogram is in agreement with the current phylogenetic classification of Gossypium species based on morphological and cytogenetic data (Endrizzi et al. 1985). The Australian diploid G. sturtianum $\left(2 \mathrm{C}_{1}\right.$ genome) is the first to be separated, followed by the cluster of the American species G. raimondii $\left(2 \mathrm{D}_{5}\right.$ genome) and $G$. thurberi ( $2 \mathrm{D}_{1}$ genome). The cultivated cotton, G. hirsutum 2(AD) , is grouped with the tri-species hybrids and the $\mathrm{BC}$ progenies (ACDD). The comparison of subsequent progenies with the cultivated parent showed that the increase of percent similarity through backcrossing and selfing is not straightforward (Table 2), indicating that the analysis of genetic similarity as performed here should facilitate the identification of BC plants in which cultivated cotton has a significant contribution at each generation.

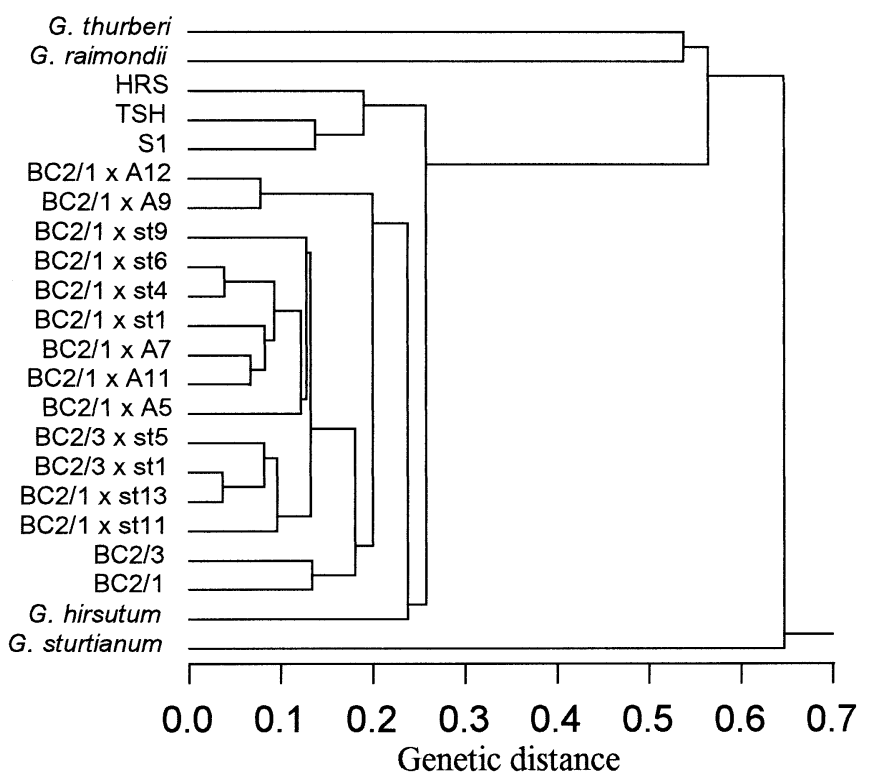

Fig. 5 Dendrogram of genetic relationships among species and progenies based on AFLP data using UPGMA and Jaccard's coefficient of similarity. Parental species, tri-species hybrids and BC generations as indicated in Table 3

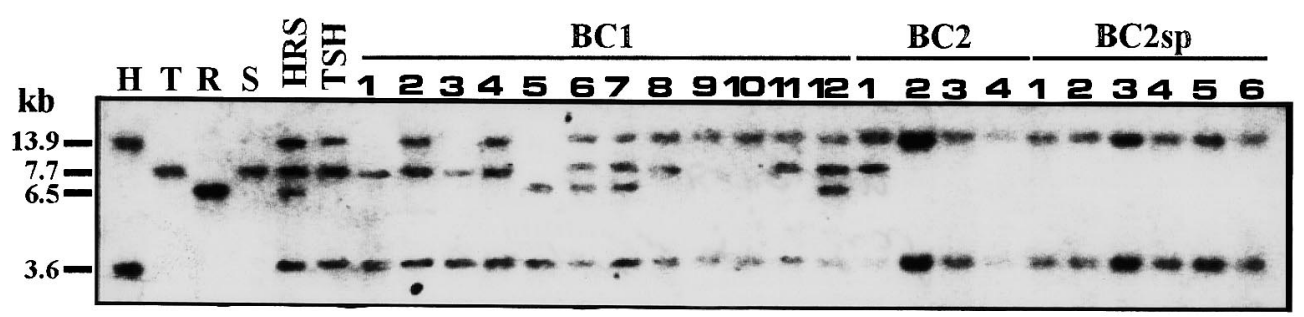

Fig. 6 RFLP patterns of parental species and progenies. DNA was digested with $X b a \mathrm{I}$ and probed with A1528 specific to linkage group D07. Parental species and tri-species hybrids as in Fig. 5. Note introgression of the 7.7-kb allele of $G$. thurberi and $G$. sturtianum, and of the $6.5-\mathrm{kb}$ allele of $G$. raimondii. BC1 numbers 1 and 3 show a replacement of the G. hirsutum $13.9-\mathrm{kb}$ allele by the 7.7-kb allele. BC1 number 5 contains a replacement of the G. hirsutum $13.9-\mathrm{kb}$ allele by the $6.5-\mathrm{kb}$ allele. BC1 numbers $6,7,12$ are heterozygous for the $13.9-\mathrm{kb}, 7.7-\mathrm{kb}, 6.5-\mathrm{kb}$ and $3.6-\mathrm{kb}$ alleles while $\mathrm{BC} 2$ numbers $2,3,4$ and $\mathrm{BC} 2 \mathrm{sp}$ are homozygous for the 13.9-kb and 3.6-kb alleles of G. hirsutum 


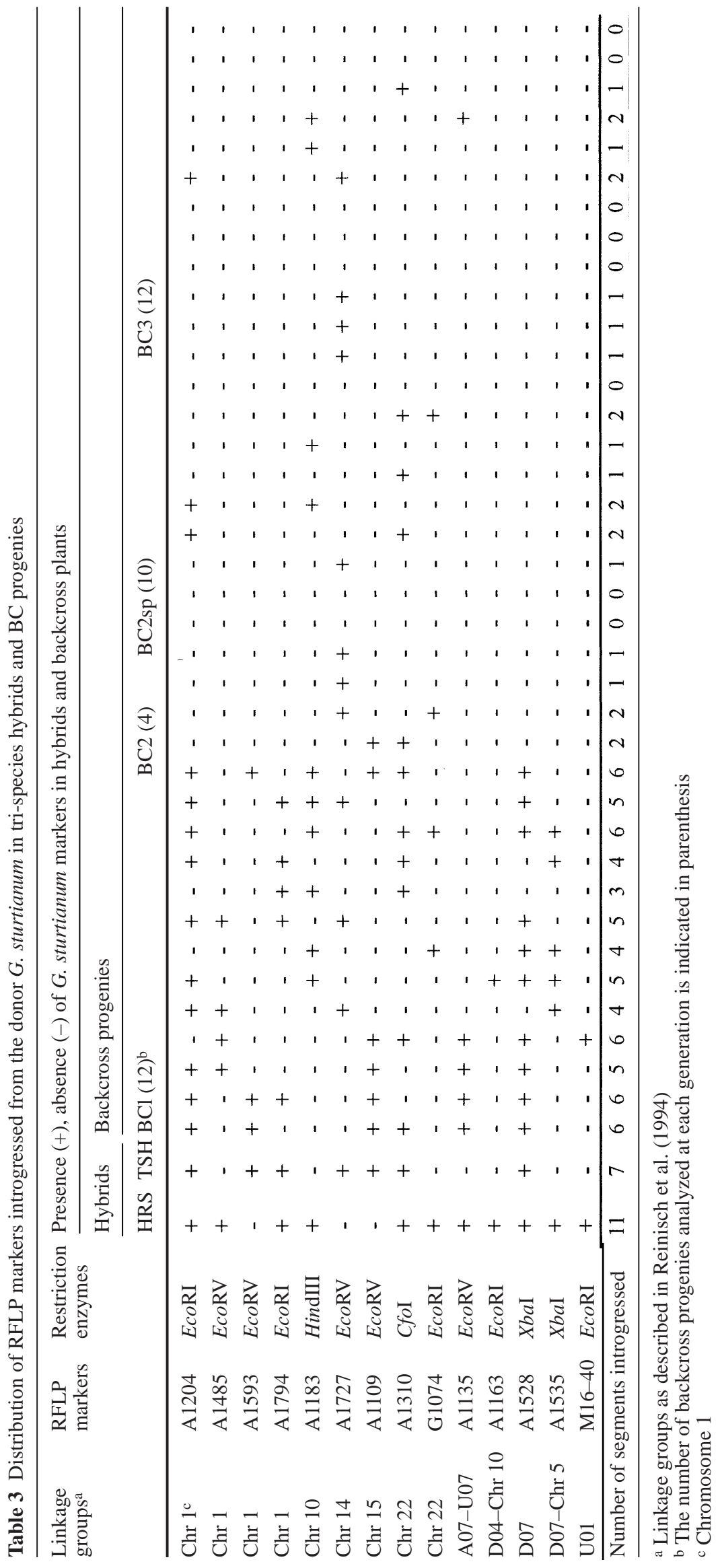


Fig. 7 Linkage groups of the RFLP map of cotton showing introgression from the donor G. sturtianum. RFLP probes checked for introgression but not detecting DNA segments of $G$. sturtianum are marked with arrowheads. DNA segments introgressed from G. sturtianum in one or more progenies are indicated by arrows and shaded boxes. The remaining markers are flanking markers of the introgressed segments, or markers placed to indicate distances in centimorgans as published in Reinisch et al. (1994)
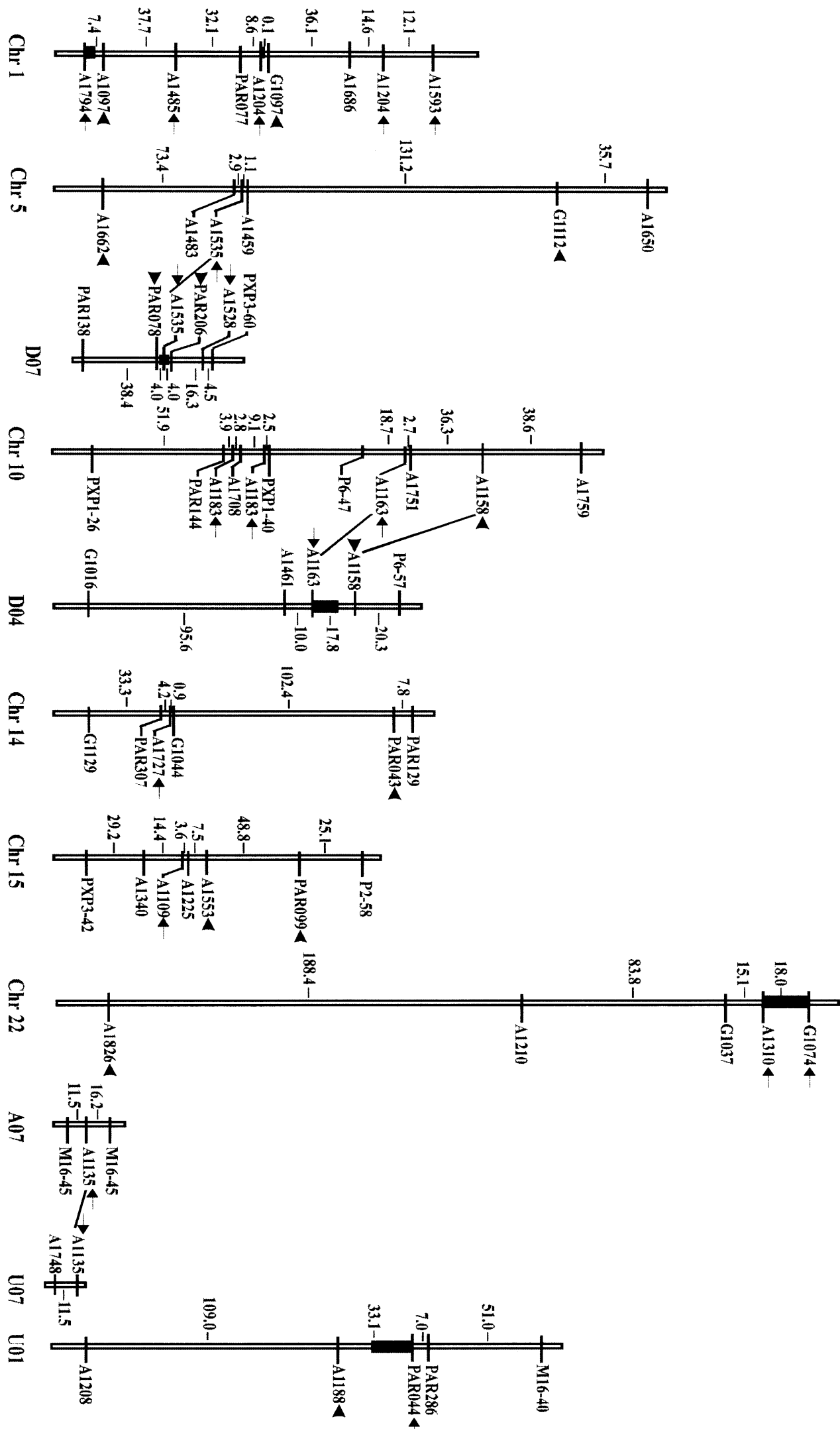
RFLP analysis

Out of the 49 RFLP markers analyzed, 14 probe/enzyme combinations (Table 3) detected introgression from the wild species ( $G$. sturtianum, $G$. thurberi, G. raimondii) into the trispecies hybrids and the $\mathrm{BC}$ progenies. Figure 6 shows the polymorphism obtained by probing with A1528 specific to linkage group D07. Analysis of RFLP patterns indicated that DNA segments were introgressed from 11 linkage groups of the donor G. sturtianum (Fig. 7). The tri-species hybrids HRS and TSH contained segments from 11 and 7 G. sturtianum linkage groups respectively (Table 3 ). The subsequent $\mathrm{BC}$ progenies segregated for these markers and no single $\mathrm{BC}$ progeny contained all the introgressed segments. The smallest introgressed segments were those detected by a single RFLP marker such as A1593 on chromosome 1, and the largest introgressed segment (18 cM long) was detected by two adjacent RFLP markers on chromosome 22 (Fig. 7). Considering all the plants together, the total size of segments introgressed from $G$. sturtianum represents approximately $51.2 \mathrm{cM}$ for the 14 probe/enzyme combinations detecting introgression from the wild parents. The positive RFLP probes showed important variation in detecting introgression from G. sturtianum. For example, probe $\mathrm{A} 1204$ on chromosome 1 detected introgression in $13 \mathrm{BC}$ progenies, while probe M16-40 on linkage group U01 detected introgression in a single $\mathrm{BC} 1$ plant (Table 3). The number of introgressed fragments varied also between generations. All the 14 G. sturtianum DNA fragments were present in the $\mathrm{BC} 1$ generation, while eight, five and five were detected in the $\mathrm{BC} 2, \mathrm{BC} 2 \mathrm{sp}$ and BC3 generations respectively (Table 3). Analysis of introgression from both bridge species ( $G$. raimondii and G. thurberi) revealed introgression of eight chromosomal segments from $G$. raimondii into HRS and seven chromosomal segments of $G$. thurberi into TSH. In the BC3 generation, five of the eight markers of G. raimondii were found, while none of the seven specific markers of G. thurberi were detected in the $\mathrm{BC} 2, \mathrm{BC} 2 \mathrm{sp}$ and $\mathrm{BC} 3$ generations (data not shown).

The introgression from wild species was of two types. In the most common type, RFLP alleles characterizing the cultivated and wild cottons were present, and the progenies were heterozygous at the introgressed locus. In the second type, one of the G. hirsutum RFLP alleles was replaced by the corresponding allele of the wild species. This last type, which is consistent with reciprocal recombination, was evident on chromosome 1 with the probes A1204 and A1593, and on linkage group D07 with the probe A1528. For example, the probe A1528 detected the 7.7-kb allele of G. thurberi and G. sturtianum in both tri-species hybrids (HRS and TSH), nine $\mathrm{BC} 1$ and one $\mathrm{BC} 2$ progenies. In two cases, the 7.7- $\mathrm{kb}$ allele replaced the $13.9-\mathrm{kb}$ allele of the upland cotton $G$. hirsutum. The same probe A1528 also detected the 6.5-kb allele of G. raimondii in four $\mathrm{BC} 1$ progenies, and in one case the $6.5-\mathrm{kb}$ allele replaced the $13.9-\mathrm{kb}$ allele of G. hirsutum (Fig. 6). The probes showing introgres- sion detected both heterozygous and homozygous progenies for the parental alleles.

\section{Discussion}

Interspecific hybridization offers great potential for the introgression of desirable traits from the numerous wild Gossypium species into cultivated cottons. However, in most cases, introgression and recombination events are not easy to trace by conventional methods. The use of molecular markers should enhance the ability of cotton breeders to monitor the introgression of specific chromosome segments that are linked to desirable traits in improved lines. We evaluated AFLP markers as tools to determine relationships in cotton germplasm. The classification of parental species established with the present AFLP data fitted the current phylogenetic pattern of the Gossypium genus. Only five combinations of primers were able to detect 477 AFLP fragments, which is higher than the 375 bands produced by 30 RAPD primers in the same parental species (Mergeai et al. 1998). Although the percentage of polymorphic bands was slightly lower for AFLP (87.4\%) than for RAPD (90.4\%), AFLP primers appeared more efficient in detecting specific markers of each wild diploid species. For instance, 70 AFLP markers specific to the donor G. sturtianum were detected, while the RAPD study revealed only 49 G. sturtianum-specific markers (Mergeai et al. 1998). AFLP is therefore a powerful technique for DNA fingerprinting in cotton, as demonstrated in other crops (Maheswaran et al. 1997; VanToai et al. 1997; Paran et al. 1998). Although the similarity of some BC progenies at the DNA level with cultivated cotton increased with backcrossing and selfing, some other progenies expressed a similarity lower than that observed between their mother parent and the upland cotton G. hirsutum. The plant having the highest coefficient of similarity $(80.5 \%)$ with cultivated cotton is a $\mathrm{BC} 3$ progeny derived from the tri-species hybrid HRS, and the genotype most remote from cultivated cotton is a BC2sp (68.1\%). Both these BC3 and BC2sp progenies were derived from a single $\mathrm{BC} 2$ sharing $75 \%$ similarity with the cultivated parent. Since genetic relatedness can be used in parental choice and mating design, the information obtained from the present study is of practical use. Introgressed individuals whose genome composition is most similar to that of cultivated cotton can be selected for the next cycle of cross. This could potentially accelerate the recovery of cultivated types (Rafalski and Tingey 1993). DNA introgression from the wild species, as evidenced by specific AFLP and RFLP markers, showed that the genomic composition of the trispecies hybrids and most of their $\mathrm{BC}$ progenies is AADC, with the D subgenome coming from $G$. hirsutum $2(\mathrm{AD})_{1}$ or from the bridge species $G$. raimondii $2 \mathrm{D}_{5}$ and $G$. thurberi $2 \mathrm{D}_{1}$. The three types of $\mathrm{D}$ chromosomes were indistinguishable in previous cytogenetic studies because of their similar shape and size (Vroh Bi et al. 1998). 
The polymorphism generated by RFLP probes allowed an easy screening of introgressed chromosomal segments. The exact numbers of linkage groups introgressed from the wild parents may be less than those reported here. For example, the three markers, A1135, A1163 and A1535, located each on two linkage groups, can indicate the presence of only one of these respective groups. Hybridization of RFLP markers also revealed that most of the introgressed progenies were heterozygous for the parental alleles. This observation is consistent with the introgression of entire chromosomes from the wild parents and/or introgression by translocations. Nevertheless, out of the 14 RFLP markers showing introgression from the wild parents, three probe/enzyme combinations detected reciprocal recombinations. Previous cytogenetic studies of the present germplasm indicated the presence of univalents of wild species and a high number of multivalents and chiasmata (Vroh Bi et al. 1998). Thus, heterozygous progenies at introgressed loci due to univalents and translocations, and reciprocal recombinations induced by homoeologous pairings were both expected in RFLP analysis. Hybridization of additional probes is however necessary to assess the rate of each introgression event. If replacements of $G$. hirsutum alleles by those of the wild species remain low, then the crossing schemes will be adapted. For example, backcrossing of the most-introgressed progenies can be alternated with cycles of selfings and cycles of random intermatings of the best plants. This breeding strategy, termed cumulative selection, could enhance recombination in hybrids built with parents which are remote genetically from each other, such as the present parental species (Demol 1981). Cumulative selection is particularly wellsuited to cotton which is both an open- and a self-pollinated crop. The number of univalents and multivalents decreased whereas bivalents increased in several BC2sp and $\mathrm{BC} 3$ plants. Some of these progenies can undergo cumulative selection since pollen fertility reached $80 \%$ (Vroh Bi et al. 1999).

Cotton is an important food crop which can contribute to solving the problem of malnutrition in several cotton-producing regions of the world. Cottonseed derivatives are however fed mainly to cattle and other ruminants because of gossypol. According to the regulations of the U.S. Food and Drug Administration (FDA), the free gossypol content of edible cottonseed products should not exceed $450 \mathrm{ppm}$ in order to fit with human consumption. The protein advisory group of the United Nations Food and Agriculture and World Health Organizations (FAO/WHO) set a maximum value of $600 \mathrm{ppm}$ (Lusas and Jividen 1987). Two different approaches are used to eliminate or minimize adverse effects of gossypol in cottonseed. The first is the development of innovative processes that can remove gossypol from the seed derivatives (Vix et al. 1971; Kadan et al. 1979; Hron and Koltun 1984; Liadakis et al. 1993). Although these procedures are efficient, they increase the oil extraction cost and decrease the nutritional value of cottonseed products by reducing bioavailable lysine. The second approach is the use of genetic research able to create cotton varieties combining both agricultural and seedprocessing needs.

The present work produced a germplasm expressing the "low-gossypol seed and high-gossypol plant" traits at different levels. Entomological research has addressed the association of cotton plant resistance with gland density and gland distribution (Hedin et al. 1992; Calhoun 1997); because the main insects avoid feeding on gossypol glands containing several toxic compounds, resistance may be achieved by developing cotton plants with a high gland density (Parrott et al. 1989; Hedin et al. 1992). Gland density in the stem, leaf and flower bud of some of the $\mathrm{BC}$ progenies presented here is higher than that of upland cotton (Vroh $\mathrm{Bi}$ et al. 1999). Considering gland distribution, the high-glanding trait (presence of gossypol glands on the calyx crown) transmitted to the tri-species hybrids and some of their progenies was reported to be useful in conferring resistance to insects such as bollworm and tobacco budworm (Wilson and Shaver 1973; Calhoun 1997). The first role of the two bridge species (D genome) in the breeding schemes was to enhance chromosome pairing in the tri-species hybrids. Their D chromosomes pair mostly with those of the D subgenome of G. hirsutum (AADD genome), so that the $\mathrm{C}$ chromosomes of G. sturtianum can pair with the A chromosomes of $G$. hirsutum (Vroh Bi et al. 1998). Beside this objective, other valuable traits such as high fiber strength, drought-, frost-, cold- and disease-resistance can also be introgressed from the wild parents (Brown and Menzel 1950; Louant 1971). The plants analyzed here are all perennial in growth habit and constitute an interesting germplasm for breeders.

Introgression of "low-gossypol seed and high-gossypol plants" from Australian wild diploid species was previously attempted (Dilday 1986; Altman et al. 1987; Shuijin and Biling 1993), but chromosomes acting for the variable expression of this trait in introgressed genetic backgrounds remain unknown. Our study is the first attempt to characterize the introgression of chromosomal segments from an Australian wild diploid cotton at the molecular level. The ability to trace regions of chromosomes from parents to offspring through multiple generations provides tools to detect linkage to agronomically important traits. Since the analyzed plants are segregating for both RFLP markers of known chromosomal locations and the desired trait, the present study is the first step towards the mapping of the "low-gossypol seed and high-gossypol plant" trait.

Acknowledgements We are grateful to Professor A.H. Paterson of Texas A\&M University (USA) for providing the RFLP markers. This research was supported by the grant 2.4565 .95 of the Belgian 'Fonds de la recherche fondamentale collective'. The $\mathrm{PhD}$ scholarship of the first author was provided by the Ministry of Scientific Research of Ivory Coast. We wish to thank Jean-Claude Martiat for his excellent technical assistance. 


\section{References}

Alford BB, Liepa GU, Vanbeber AD (1996) Cottonseed protein: what does the future hold? Plant Food Hum Nutr 49:1-11

Altman DW, Stelly DM, Kohel RJ (1987) Introgression of the glanded-plant and glandless-seed trait from Gossypium sturtianum Willis into cultivated upland cotton using ovule culture. Crop Sci 27:880-884

Altman DW, Stipanovic RD, Bell AA (1990) Terpenoids in foliar pigment glands of $\mathrm{A}, \mathrm{D}$, and $\mathrm{AD}$ genome cottons: introgression potential for pest resistance. J Hered 81:447-454

Becker J, Vos P, Kuiper M, Salamini F, Heun M (1995) Combined mapping of AFLP and RFLP markers in barley. Mol Gen Genet 249:65-73

Brown MS, Menzel MY (1950) New tri-species hybrids in cotton. J Hered 41:291-295

Brubaker CL, Benson CG, Miller C, Leach DN (1996) Occurrence of terpenoid aldehydes and lysigenous cavities in the 'glandless' seeds of Australian Gossypium species. Aust J Bot 44:601-612

Calhoun DS (1997) Inheritance of high glanding, an insect resistance trait in cotton. Crop Sci 37:1181-1186

Demol J (1981) La sélection cumulative. Application aux plantes autogames. Un exemple: l'amélioration du cotonnier. Ann Gembloux 87:167-181

Dilday RH (1986) Development of a cotton plant with glandless seeds, and glanded foliage and fruiting forms. Crop Sci 26:639-641

Dudley JW (1993) Molecular markers in plant improvement: manipulation of genes affecting quantitative traits. Crop Sci 33:660-668

Endrizzi JE, Turcotte EL, Kohel RJ (1985) Genetics, cytology, and evolution of Gossypium. Adv Genet 23:271-375

Garcia GM, Stalker HT, Kochert G (1995) Introgression analysis of an interspecific hybrid population in peanuts (Arachis hypogaea L.) using RFLP and RAPD markers. Genome 38:166176

Hansen M, Kraft T, Christiansson M, Nilson NO (1999) Evaluation of AFLP in Beta. Theor Appl Genet 98:845-852

Hedin PA, Parrott WL, Jenskins JN (1992) Relationships of glands, cotton square terpenoid aldehydes, and other allelochemicals to larval growth of Heliothis virescens (Lepidoptera: Noctuidae). J Econ Entomol 85:359-364

Hron RJ, Koltun SP (1984) An aqueous ethanol extraction process for cottonseed oil. J Am Oil Chem Soc 61:1457-1460

Iqbal MJ, Aziz N, Saeed NA, Zafar Y (1997) Genetic diversity evaluation of some elite cotton varieties by RAPD analysis. Theor Appl Genet 94:139-144

Jaccard P (1908) Nouvelles recherches sur la distribution florale. Bull Soc Vaud Sci Nat 44:223-270

Jena KK, Klush GS, Kochert G (1992) RFLP analysis of rice (Oryza sativa L.) introgression lines. Theor Appl Genet $84: 608-616$

Kadan RS, Freeman DW, Ziegler Jr GM, Spadaro JJ (1979) Air classification of defatted, glanded cottonseed flours to produce edible protein product. J Food Sci 44:1522-1524

Lee M (1998) Genome projects and gene pools: new germplasm for plant breeding? Proc Natl Acad Sci USA 95:2001-2004

Liadakis GN, Floridis A, Tzia C, Oreopoulou V (1993) Protein isolates with reduced gossypol content from screw-pressed cottonseed meal. J Agric Food Chem 41:918-922

Louant BP (1971) Recherches sur les possibilités d'améliorer le cotonnier par l'introgression directe de caractères provenant de Gossypium raimondii Ulbr. PhD thesis, Faculté des Sciences Agronomiques de l'Etat, Gembloux, Belgique

Lusas EW, Jividen GM (1987) Glandless cottonseed: a review of the first 25 years of processing and utilization research. J Am Oil Chem Soc 64:839-854

Maheswaran M, Subudhi PK, Nandi S, Xu JC, Parco A, Yang DC, Huang N (1997) Polymorphism, distribution, and segregation of AFLP markers in a doubled-haploid rice population. Theor Appl Genet 94:39-45
McMichael SC (1960) Combined effects of glandless genes $g l_{2}$ and $g l_{3}$ on pigment glands in the cotton plant. Agron $\mathbf{J}$ $52: 385-386$

Meksem K, Leister D, Peleman J, Zabeau M, Salamini F, Gebhardt C (1995) A high-resolution map of the vicinity of the RI locus on chromosome $\mathrm{V}$ of potato based on RFLP and AFLP markers. Mol Gen Genet 249:74-81

Meredith JWR, Brown JS (1998) Heterosis and combining ability of cottons originating from different regions of the United States. J Cotton Sci 2:77-84 (http://www.jcotsci.org)

Mergeai G (1992) Nouvelles perspectives concernant la méthodologie à suivre pour l'introgression chez le cotonnier cultivé (Gossypium hirsutum L.) du caractère retard à la morphogenèse des glandes à gossypol. Cotton Fib Trop 47:113119

Mergeai G, Vroh Bi I, Baudoin JP, du Jardin P (1998) Use of random amplified polymorphic DNA (RAPD) markers to assist wide hybridization in cotton. In: Bajaj YPS (ed) Biotechnology in agriculture and forestry, Cotton. Springer-Verlag, Berlin Heidelberg, pp 121-139

Multani DS, Lyon BR (1995) Genetic fingerprinting of Australian cotton cultivars with RAPD markers. Genome 38:1005-1008

Paran I, Aftergoot E, Shifriss C (1998) Variation in Capsicum revealed by RAPD and AFLP markers. Euphytica 99:167173

Parrott WL, Jenkins JN, Mulrooney JE, Jack C, McCarty J, Shepherd L (1989) Relationship between gossypol gland density on cotton squares and resistance to tobacco budworm (Lepidoptera: Noctuidae) larvae. J Econ Entomol 82:589-592

Paterson AH, Tanksley SD, Sorrells ME (1991) DNA markers in plant improvement. Adv Agron 46:39-90

Rafalski JA, Tingey SV (1993) Genetic diagnostics in plant breeding: RAPDs, microsatellites and machines. Trends Genet 9:275-280

Reinisch AJ, Dong J-M, Brubaker CL, Stelly DM, Wendel JF, Paterson AH (1994) A detailed map of cotton, Gossypium hirsutum $\times$ Gossypium barbadense: chromosome organization and evolution in a disomic polyploid genome. Genetics 138:829_ 847

Shan X, Blake TK, Talbert LE (1999) Conversion of AFLP markers to sequence-specific PCR markers in barley and wheat. Theor Appl Genet 98:1072-1078

Shappley ZW, Jenkins JN, Watson Jr CE, Kahler AL, Meredith WR (1996) Establishment of molecular markers and linkage groups in two $\mathrm{F}_{2}$ populations of upland cotton. Theor Appl Genet 92:915-919

Shuijin Z, Biling L (1993) Studies of introgression of the "glandless seeds-glanded plant" trait from Gossypium bickii into cultivated upland cotton (G. hirsutum). Cotton Fib Trop 48:195199

Stewart JM (1994) Potential for crop improvement with exotic germplasm and genetic engineering. In: Constable GA, Forester NW (eds) Proc World Cotton Research Conference-1. CSIRO, Brisbane, Australia, pp 313-327

Stipanovic RD, Bell AA, Mace ME, Howel CR (1975) Antimicrobial terpenoids of Gossypium: 6-metoxygossypol and 6,6'dimetoxygossypol. Phytochemistry 14:1077-1081

Tanskley SD, Young ND, Paterson A, Bonierbale MW (1989) RFLP mapping in plant breeding: new tools for an old science. Bio/Technology 7:257-264

Tatineni V, Cantrell RG, Davis DD (1996) Genetic diversity in elite cotton germplasm determined by morphological characteristic and RAPDs. Crop Sci 36:186-192

Texier PH (1993) Le coton, cinquième producteur mondial d'huile alimentaire. Cotton Dev 8:2-3

Thomas C, Vos P, Zabeau M, Jones D, Norcott K, Chadwick B, Jones J (1995) Identification of amplified restriction fragment polymorphism (AFLP) markers tightly linked to the tomato CF-9 gene for resistance to Cladosporium fulvum. Plant J 8:785-794

VanToai TT, Peng J, Martin SKS (1997) Using AFLP markers to determine the genomic contribution of parents to populations. Crop Sci 37:1370-1373 
Vix HLE, Eaves PH, Gardner Jr HK, Lambou MG (1971) Degossypolized cottonseed flour. The liquid cyclone process. J Am Oil Chem Soc 48:611-615

Vos P, Hogers R, Bleeker M, Reijans M, van der Lee T, Hornes M, Frijters A, Pot J, Peleman J, Kuiper M, Zabeau M (1995) AFLP: a new technique for DNA fingerprinting. Nucleic Acids Res 23:4407-4414

Vroh Bi I, Chandellier A, Mergeai G, du Jardin P (1996) Improved RAPD amplification of recalcitrant plant DNA by the use of activated charcoal during DNA extraction. Plant Breed 115:205-206

Vroh Bi I, du Jardin P, Mergeai G, Baudoin JP (1997) Optimization and application of RAPD (random amplified polymorphic DNA) in a recurrent selection programme of cotton (Gossypium spp.). Biotechnal Agron Soc Environ 1:142-150

Vroh Bi I, Baudoin JP, Mergeai G (1998) Cytogenetics of the 'glandless-seed and glanded-plant' trait from Gossypium sturtianum Willis introgressed into upland cotton (Gossypium hirsutum L.). Plant Breed 117:235-241
Vroh Bi I, Baudoin JP, Hau B, Mergeai G (1999) Development of high-gossypol cotton plants with low-gossypol seeds using trispecies bridge crosses and in vitro culture of seed embryos. Euphytica 106:243-251

Wang GL, Dong JM, Paterson AH (1995) The distribution of Gossypium hirsutum chromatin in G. barbadense germplasm: molecular analysis of introgressive plant breeding. Theor Appl Genet 91:1153-1161

Wilson FD, Shaver TN (1973) Glands, gossypol content and tobacco budworm development in seedlings and floral parts of cotton. Crop Sci 13:107-110

Zabeau M (1993) Selective restriction fragment amplification: a general method for DNA fingerprinting. In: European Patent Application number 92402629.7, Publication number 0534858 A1

Zhu J, Gale MD, Quarrie S, Jackson MT, Bryan GJ (1998) AFLP markers for the study of rice biodiversity. Theor Appl Genet 96:602-611 